Table 1. CLASI-50 Response Rates by Subgroups at Week 24

\begin{tabular}{|c|c|c|c|c|c|c|c|}
\hline & & \multicolumn{2}{|r|}{$0.15 \mathrm{mg}$ QD } & \multicolumn{2}{|r|}{$0.3 \mathrm{mg}$ QD } & \multicolumn{2}{|r|}{$0.45 \mathrm{mg} Q D$} \\
\hline & & \multicolumn{2}{|r|}{$(n=42)$} & \multicolumn{2}{|r|}{$(n=82)$} & \multicolumn{2}{|r|}{$(n=81)$} \\
\hline & Placebo & & & & & & \\
\hline \multirow[t]{3}{*}{ Subgroup } & $(n=83)$ & \multicolumn{2}{|c|}{$0.15 \mathrm{mg}$ QD vs Placebo } & \multicolumn{2}{|c|}{$0.3 \mathrm{mg}$ QD vs Placebo } & \multicolumn{2}{|c|}{$0.45 \mathrm{mg}$ QD vs Placebo } \\
\hline & & & Str Diff in \% (95\% Cl) & & Str Diff in \% $(95 \% \mathrm{Cl})$ & & Str Diff in \% (95\% Cl) \\
\hline & $\mathrm{n} / \mathrm{m}(\%)$ & $\mathrm{n} / \mathrm{m}(\%)$ & $P$ value & $\mathrm{n} / \mathrm{m}(\%)$ & $P$ value & $\mathrm{n} / \mathrm{m}(\%)$ & $P$ value \\
\hline All pts & $37 / 83(44.6)$ & $19 / 42(45.2)$ & $0.4(-17.33,18.55) P=0.961$ & $41 / 82(50.0)$ & $5.3(-9.93,20.11) P=0.499$ & $45 / 81(55.6)$ & $10.9(-4.30,25.51) P=0.163$ \\
\hline CLASI-A $\geq 8$ & $10 / 20(50.0)$ & $8 / 13(61.5)$ & $15.9(-17.42,45.45) P=0.399$ & $13 / 24(54.2)$ & $12.1(-17.57,39.97) P=0.458$ & $16 / 24(66.7)$ & $15.1(-15.51,42.49) P=0.368$ \\
\hline ACLE & $23 / 50(46.0)$ & $15 / 30(50.0)$ & $4.8(-17.22,26.31) P=0.662$ & $20 / 43(46.5)$ & $-3.3(-22.95,16.67) P=0.738$ & $17 / 38(44.7)$ & $-3.0(-23.20,17.65) P=0.782$ \\
\hline SCLE & 9/17 (52.9) & $5 / 9(55.6)$ & $2.6^{\mathrm{a}}(-33.04,36.33) P=0.966$ & $3 / 9(33.3)$ & $-6.6(-38.98,31.86) P>0.999$ & $11 / 12(91.7)$ & $38.7^{\mathrm{a}}(4.54,61.75) P=0.035$ \\
\hline CCLE & $5 / 18(27.8)$ & $7 / 14(50.0)$ & $22.2^{\mathrm{a}}(-10.51,50.00) P=0.198$ & $10 / 23(43.5)$ & $23.8(-6.89,48.88) P=0.129$ & $18 / 29(62.1)$ & $34.1(4.43,56.16) P=0.029$ \\
\hline
\end{tabular}

$\mathrm{Cl}$, confidence interval; Str Diff, stratified difference. ${ }^{a}$ Unstratified difference.

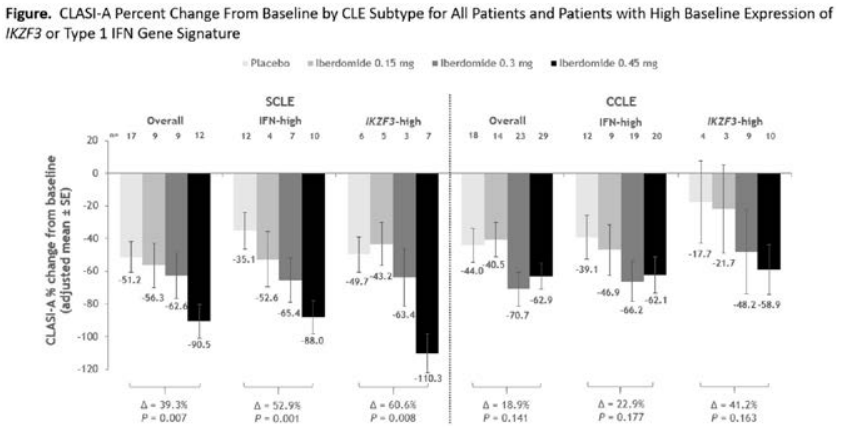

$\Delta$, treatment difference of adjusted means; CCLE, chronic cutaneous lupus erythematosus; CLASI-A, Cutaneous Lupus Erythematosus Disease Area and Severity Index-activity score; IFN, interferon; SCLE, subacute cutaneous lupus erythematosus.

Acknowledgements: This study was sponsored by Bristol Myers Squibb. Professional medical writing assistance was provided by Peloton Advantage, LLC, an OPEN Health company, and funded by Bristol Myers Squibb.

Disclosure of Interests: Victoria Werth Consultant of: Bristol Myers Squibb, Grant/research support from: Bristol Myers Squibb, Joan Merrill Consultant of: UCB, GlaxoSmithKline, AbbVie, EMD Serono, Remegen, Celgene/Bristol Myers Squibb, AstraZeneca, Lilly, Immupharma, Amgen, Janssen, Resolve, Alpine, Aurinia, Astellas, Alexion, and Provention, Grant/research support from: GlaxoSmithKline and AstraZeneca, Richard Furie Consultant of: Bristol Myers Squibb, Grant/research support from: Bristol Myers Squibb, Thomas Dörner Consultant of: support for clinical studies and honoraria for scientific advice: AbbVie, Bristol Myers Squibb Company, Celgene, Eli Lilly, Janssen, Novartis, Roche, Employee of: Charite Universitätsmedizin, Berlin and DRFZ Berlin, Germany, Ronald van Vollenhoven Speakers bureau: UCB, AbbVie, Galapagos, Janssen, Pfizer, Paid instructor for: support for educational programs: Pfizer, Roche, Consultant of: AstraZeneca, Biogen, Biotest, Celgene, Gilead, Servier, UCB, AbbVie, Galapagos, Janssen, Pfizer, Grant/research support from: Bristol Myers Squibb, GlaxoSmithKline, Eli Lilly, UCB, Peter Lipsky Employee of: RILITE Foundation, Michael Weiswasser Shareholder of: Bristol Myers Squibb, Employee of: Bristol Myers Squibb, Shimon Korish Shareholder of: Bristol Myers Squibb, Employee of: Bristol Myers Squibb, Peter Schafer Shareholder of: Bristol Myers Squibb, Employee of: Bristol Myers Squibb, Mark Stern Shareholder of: Bristol Myers Squibb, Employee of: Bristol Myers Squibb, Zhaohui Liu Shareholder of: Bristol Myers Squibb, Employee of: Bristol Myers Squibb, Shaojun Tang Shareholder of: Bristol Myers Squibb, Employee of: Bristol Myers Squibb, Nikolay Delev Shareholder of: Bristol Myers Squibb, Employee of: Bristol Myers Squibb

DOI: 10.1136/annrheumdis-2021-eular.2181

\section{OP0133 THE PREVALENCE AND RISK FACTORS OF RETINAL TOXICITY ASSOCIATED WITH LONG-TERM HYDROXYCHLOROQUINE USE}

S. Do ${ }^{1}$, J. H. Du ${ }^{2}$, J. X. An ${ }^{3}$, J. Wang ${ }^{4}$, A. Lin ${ }^{5} .{ }^{1}$ Western University of Health Sciences, School of Pharmacy, Pomona, United States of America; ${ }^{2}$ Kaiser Permanente Fontana Medical Center, Department of Pharmacy, Fontana,
United States of America; ${ }^{3}$ Kaiser Permanente Research \& Evaluation, Department of Research and Evaluation, Pasadena, United States of America; ${ }^{4}$ Kaiser Permanente Fontana Medical Center, Department of Ophthalmology, Fontana, United States of America; ${ }^{5}$ Kaiser Permanente Southern California, Department of Rheumatology, Fontana, United States of America

Background: Hydroxychloroquine ( $\mathrm{HCQ}$ ) is commonly used for the treatment of various autoimmune diseases. The medication is generally well-tolerated. However, long-term use after 5 years may increase the risk of retinopathy. One study in 2014 has demonstrated the risk can be as high as $7.5 \%$. Optical Coherence Tomography (OCT) has become a major modality in screening retinopathy.

Objectives: To evaluate the prevalence of retinal toxicity among patients using hydroxychloroquine and to determine various risk factors associated with hydroxychloroquine-associated retinal toxicity.

Methods: We performed a retrospective chart review on a cohort of adult patients with long-term use ( $\geq 5$ years cumulative) of HCQ between January $1^{\text {st }}, 2011$ to December $31^{\text {st }}, 2018$ from the Kaiser Permanente San Bernardino County and Riverside medical center areas in Southern California, USA. Patients were excluded if they had previously been diagnosed with retinopathy prior to hydroxychloroquine use, were deceased, or had incomplete OCT exam. Our primary endpoint was the prevalence of patients who developed retinal toxicity detected by OCT, and later confirmed by retinal specialist. Potential risk factors (age, duration of therapy, daily consumption per actual body weight, cumulative dose, confounding diseases and medication) for developing retinopathy were also evaluated. Univariable and multivariable logistic regression analyses were used to determine risk factors associated with retinal toxicity.

Results: Among 676 patients exposed to more than 5 years of $\mathrm{HCQ}$, the overall prevalence of retinal toxicity was $6.8 \%$, and ranged from $2.5 \%$ to $22.2 \%$ depending on the age, weight-based dosing, duration of use and cumulative dose. Duration of therapy for 10 years or more increased risk of retinopathy by approximately 5 to 19 folds. Similarly, weight-based dose of $7 \mathrm{mg} / \mathrm{kg} /$ day or greater was assciated with increased risk of retinopathy by approximately 5 times. Patients with cumulative dose of 2000 grams or more had greater than 15 times higher risk of developing retinopathy. Duration of use for10 years or more (odd ratio 4.32, $95 \% \mathrm{Cl} 1.99-12.49$ ), age (odd ratio 1.04; 95\% Cl 1.01 - 1.08), cumulative dose of more than $1500 \mathrm{~g}$ (odd ratio $7.4 ; 95 \% \mathrm{Cl} 1.40-39.04$ ) and atherosclerosis of the aorta (odd ratio $2.59 ; 95 \% \mathrm{Cl}, 1.24-5.41$ ) correlated with higher risk of retinal toxicity.

\begin{tabular}{|c|c|c|c|c|c|}
\hline & \multicolumn{2}{|c|}{ No Retinal Toxicity ( $\mathrm{N}=630$ ) } & \multicolumn{2}{|c|}{ Retinal Toxicity $(\mathrm{N}=46$ ) } & \multirow[b]{2}{*}{ p-value } \\
\hline & Mean & Std Dev & Mean & Std Dev & \\
\hline Dose per day (mg) & 326.6 & 96.2 & 337 & 92.8 & 0.479 \\
\hline Dose per kg/day & 4.3 & 1.4 & 4.9 & 1.7 & 0.003 \\
\hline \multicolumn{6}{|l|}{ Duration of use } \\
\hline Months & 99.3 & 33.4 & 141.5 & 64.5 & $<0.0001$ \\
\hline Years & 8.3 & 2.8 & 11.8 & 5.4 & $<0.0001$ \\
\hline Cumulative dose (mg) & 983.2 & 445.2 & 1483.6 & 891.5 & $<0.0001$ \\
\hline
\end{tabular}

Conclusion: The overall prevalence of retinopathy was $6.8 \%$. Regular OCT screening, especially in patients with hydroxychloroquine use for more than 10 years, daily intake $>7 \mathrm{mg} / \mathrm{kg}$, or cumulative dose $>1500$ grams is important in detecting hydroxychloroquine-associated retinal toxicity 
Prevalence of HCQ Retinopathy Stratified by Cumulative Dose (g)

$\approx$ No HCQ retinopathy $\%$ HCQ retinopathy $120.0 \%$

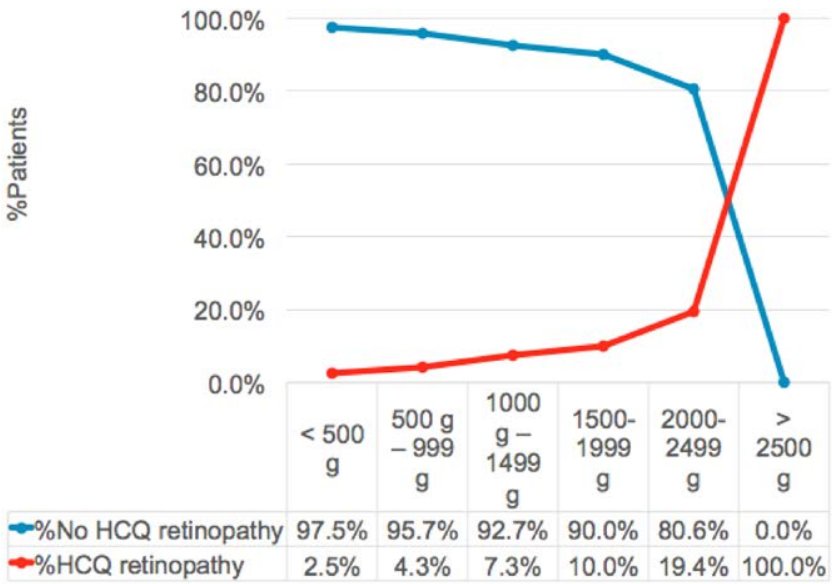

REFERENCES:

[1] Hobbs HE. Sorsby A, \& Freedman A. Retinopathy Following Chloroquine Therapy. The Lancet. 1959; 2(7101): 478-480.

[2] Levy, G. D., Munz, S. J., Paschal, J., Cohen, H. B., Pince, K. J., \& Peterson, T. Incidence of hydroxychloroquine retinopathy in 1,207 patients in a large multicenter outpatient practice. Arthritis \& Rheumatism: 1997; 40(8): 1482-1486.

[3] Ding, H. J., Denniston, A. K., Rao, V. K., \& Gordon, C. Hydroxychloroquine-related retinal toxicity. Rheumatology. 2016; 55(6): 957-967.

[4] Stelton, C. R., Connors, D. B., Walia, S. S., \& Walia, H. S. Hydrochloroquine retinopathy: characteristic presentation with review of screening. Clinical rheumatology. 2013; 32(6): 895-898.

[5] Marmor, M. F., Kellner, U., Lai, T.Y., Melles, R. B., \& Mieler, W. F. Recommendations on screening for chloroquine and hydroxychloroquine retinopathy (2016 revision). Ophthalmology. 2016; 123(6): 1386-1394

[6] Melles, R. B., \& Marmor, M. F. The risk of toxic retinopathy in patients on long-term hydroxychloroquine therapy. JAMA ophthalmology. 2014; 132(12): 1453-1460.

Disclosure of Interests: None declared

DOI: 10.1136/annrheumdis-2021-eular.328

\section{OP0134 NOVEL INTERFERON GENE EXPRESSION SCORES PREDICT REFRACTORY SEVERE CUTANEOUS DISEASE FOLLOWING RITUXIMAB THERAPY IN SLE}

L. M. Carter ${ }^{1}$, A. Alase2, Z. Wigston2, A. Psarras2, A. Burska2, M. Y. MD Yusof2, E. Hensor2, J. Reynolds ${ }^{3}$, M. Wittmann2, I. N. Bruce ${ }^{4}$, E. Vital2on behalf of The MASTERPLANS Consortium. ${ }^{1}$ University of Leeds, Leeds Institute of Rheumatic and Musculoskeletal Medicine, Leeds, United Kingdom; ${ }^{1}$ University of Leeds, Leeds Institute of Rheumatic and Musculoskeletal Medicine, Leeds, United Kingdom; ${ }^{3}$ University of Birmingham, Institute of Inflammation and Ageing, Birmingham, United Kingdom; ${ }^{4}$ University of Manchester, Division of Musculoskeletal \& Dermatological Sciences, Manchester, United Kingdom

Background: We developed and validated two continuous interferon-stimulated gene (ISG) expression scores (IFN-Score-A and IFN-Score-B) that predict clinical outcomes in SLE. IFN-Score-A includes ISGs typically present in a global interferon signature while IFN-Score-B includes additional ISGs potentially responsive to multiple IFN subtypes [1]

We have previously shown that these scores associate with treatment response following rituximab (RTX) therapy within the British Isles Lupus Assessment Group (BILAG) Biologics Register (BILAG-BR), a UK wide study of patients treated with RTX for active SLE following cyclophosphamide and/ or mycophenolate mofeti treatment failure. Specifically, multivariable analysis showed higher baseline IFNScore-B independently predicted BILAG response at 6 months post treatment [2] We also showed that response of cutaneous lupus to RTX can be poor even when other organs respond well, and that interferons are enriched in the skin of patients with SLE where dysregulated keratinocytes are a source of IFNK [3]. MASTERPLANS is a consortium aimed at identifying therapeutic biomarkers in SLE.

Objectives: To investigate how IFN-Score-A and -B associated with skin disease and response to RTX.
Methods: Pre-treatment whole blood samples were collected in TEMPUS tubes from subjects undergoing first RTX treatment within BILAG-BR. IFN-Scores were derived using a custom Taqman array as previously described [1]. Clinical response was defined as improvement in BILAG-2004 disease activity, with a maximum of one domain showing persistent BILAG-2004 grade B disease, and no new BILAG grade $A$ or $B$ disease flares at 6 months. The mucocutaneous domain of BILAG was then analysed separately.

Results: 147 patients were studied, of whom 90 had follow up data available. Baseline BILAG-2004 grade A/B disease activity predominantly affected the mucocutaneous domain in 74/147 (50.3\%), musculoskeletal in $61 / 147(41.5 \%)$ and renal domain $66 / 147(37.4 \%)$.

At 6 months 59/90 (65.6\%) achieved an overall treatment response. Responders showed significantly higher mean IFN-Score-B compared with non-responders $(-1.8$ vs $-2.4, p=0.04)$. Among those with active grade A/B BILAG-2004 mucocutaneous disease at baseline, $38 / 50(76 \%)$ showed improvement within this domain at 6 months. However, among overall non-responders, 7/31 (22.6\%) had new or residual BILAG-A mucocutaneous disease at 6 months post RTX indicating it to be a substantial component of overall treatment failure. In contrast persistent grade A musculoskeletal disease was seen in $9.7 \%$ of non-responders. BILAG-A mucocutaneous disease is characterised by severe manifestations including extensive rashes covering $>18 \%$ of body surface area, severe bullous lupus or panniculitis and disabling deep mucosal ulceration. Neither IFN-Score-A nor IFN-Score-B were significantly associated with the severity of mucocutaneous disease at baseline. However, individuals with persistent or new BILAG-A mucocutaneous disease at six months following RTX displayed significantly lower baseline IFN-Score-B than those with improving or residual less severe disease ( -3.0 vs $-2.1, p=0.04)$ after RTX

Conclusion: Low IFN score-B status identified an endotype of severe mucocutaneous SLE which was resistant to RTX therapy in the BILAG-BR cohort. We previously showed that high IFN-score-B independently predicts overall therapeutic response to rituximab. Further work will aim to refine IFN status as overall and organ specific biomarkers in SLE.

\section{REFERENCES:}

[1] El-Sherbiny et al., Sci. Rep. 2018; 8: 5793.

[2] Alase et al., ARD 2019;78:763-764

[3] Psarras et al., Nat Commun. 2020; 11: 6149

Acknowledgements: We would like to thank the Medical Research Council, National Institute of Health Research, UK for funding the MASTERPLANS project Disclosure of Interests: Lucy Marie Carter: None declared, Adewonuola Alase: None declared, Zoe Wigston: None declared, Antonios Psarras: None declared, Agata Burska: None declared, Md Yuzaiful Md Yusof: None declared, Elizabeth Hensor: None declared, John Reynolds: None declared, Miriam Wittmann Consultant of: Abbvie, Celgene, Janssen, L'Oreal, Novartis and Pfizer, lan N. Bruce Speakers bureau: GlaxoSmithKline, UCB Pharma, Consultant of: AstraZeneca, Eli Lilly, GlaxoSmithKline, ILTOO Pharma, Medlmmune, Merck Serono, Grant/ research support from: Genzyme Sanofi, GlaxoSmithKline, Edward Vital Consultant of: Roche, GSK and AstraZeneca, Grant/research support from: Roche, GSK and AstraZeneca

DOI: 10.1136/annrheumdis-2021-eular.1098

\section{OP0135 SAFETY AND EFFICACY OF SUBCUTANEOUS BELIMUMAB AND INTRAVENOUS RITUXIMAB COMBINATION IN PATIENTS WITH PRIMARY SJÖGREN'S SYNDROME: A PHASE 2, RANDOMISED, PLACEBO-CONTROLLED 68-WEEK STUDY}

X. Mariette ${ }^{1}$, C. Baldini ${ }^{2}$, F. Barone ${ }^{3}$, H. Bootsma ${ }^{4}$, K. Clark ${ }^{5}$, S. De Vita ${ }^{6}$ K. Lerang ${ }^{7}$, P. Mistry ${ }^{8}$, F. Morin ${ }^{9}$, R. Punwaney ${ }^{10}$, R. Seror ${ }^{1}$, P. L. Van Daele $^{11}$, A. Van Maurik ${ }^{12}$, N. Wisniacki ${ }^{13}$, D. Roth ${ }^{14}$. ${ }^{1}$ Université Paris-Saclay, Rheumatology, Paris, France; ${ }^{2}$ University of Pisa, Rheumatology Unit, Department of Clinical and Experimental Medicine, Pisa, Italy; ${ }^{3}$ University of Birmingham, College of Medical and Dental Sciences, Rheumatology, Birmingham, United Kingdom: ${ }^{4}$ University of Groningen, University Medical Center Groningen, Rheumatology and Clinical Immunology, Groningen, Netherlands; ${ }^{5}$ GlaxoSmithKline, Clinical Science, Stevenage, United Kingdom; ${ }^{6}$ Azienda Ospedaliera Universitaria di Udine, Rheumatology Clinic, Department of Medical Area, Udine, Italy: ${ }^{7}$ Oslo University Hospital, Department of Rheumatology, Oslo, Norway; ${ }^{8}$ GlaxoSmithKline, R\&D Biostatistics, Stevenage, United Kingdom; ${ }^{9}$ Centre de Recherche Musculo-Squelettique, Centre de Recherche Musculo-Squelettique, Trois Rivieres, Canada; ${ }^{10}$ GlaxoSmithKline, Pharmaceutical Research and Development, Philadelphia, PA, United States of America; ${ }^{11}$ Erasmus Medical Center, Department of Internal Medicine and Department of Immunology, Rotterdam, Netherlands: ${ }^{12}$ GlaxoSmithKline, Clinical Pharmacology and Experimental Medicine, Stevenage, United Kingdom; ${ }^{13}$ GlaxoSmithKline, Discovery Medicine, Stevenage, United Kingdom ${ }^{14}$ GlaxoSmithKline, Research and Development, Collegeville, PA, United States of America 